\title{
Validation of the Double Mediation Model of Workplace Well-Being on the Subjective Well-Being of Technological Employees
}

\author{
Shu-Ya Chang* and Hsiang-Chen Hsu \\ Department of Industrial Management, I-Shou University, Kaohsiung, Taiwan
}

\section{OPEN ACCESS}

Edited by:

Shih-Chih Chen,

National Kaohsiung University of Science and Technology, Taiwan

Reviewed by:

Maosheng Yang,

Beijing Jiaotong University,

China

Haiyan Song,

Huzhou Vocational and Technical College, China

*Correspondence:

Shu-Ya Chang

r969@ms76.hinet.net

Specialty section:

This article was submitted to

Organizational Psychology,

a section of the journal

Frontiers in Psychology

Received: 18 December 2021

Accepted: 14 January 2022

Published: 07 February 2022

Citation:

Chang S-Y and Hsu H-C (2022) Validation of the Double Mediation Model of Workplace Well-Being on

the Subjective Well-Being of Technological Employees.

Front. Psychol. 13:838723.

doi: 10.3389/fpsyg.2022.838723
In recent years, workplace well-being has been a popular research topic, because it is helpful to promote employees' welfare, thereby bringing valuable personal and organizational outcomes. With the development of technology, the technology industry plays an important role in Taiwan. Although the salary and benefits provided by the technology industry are better than other industries, the work often requires a lot of time and effort. It is worth paying attention to whether a happy workplace will bring subjective well-being for the technology industry in Taiwan. This study explored the influence of workplace well-being, job involvement, and flow on the subjective well-being. The research was conducted by a questionnaire survey. A total of 256 employees in the technology industry in the Nanzi Processing Zone in Kaohsiung City, Taiwan were surveyed. Collected data were analyzed by statistical methods, such as multivariate and structural equation models. The study results indicated that workplace well-being, flow, and job involvement have a positive and significant impact on the subjective well-being. In addition to having a direct impact on subjective well-being, flow is also a significant variable to mediate the impact of workplace well-being to subjective well-being. In addition, job involvement also affects subjective well-being through flow, which means that the state of selflessness at work is the most important factor affecting subjective well-being. Finally, based on the research findings, the researcher provided practical suggestions to the government and the technology industry.

Keywords: workplace well-being, job involvement, flow, subjective well-being, technological employee

\section{INTRODUCTION}

The advance of new technology makes humans live better. However, the development of technology relied on the dedication of employees who worked in the high-tech industry. According to a survey conducted by the Human Resources Bank of Taiwan, there are nearly 6 million overwork employees worked under high pressure in three major industries, including finance, technology, and communications.

They usually worked overtime and which caused them to have health problems, such as cardiovascular disease or stroke because of the high pressure of the industry. However, people ignore the pressure of the technology industry because its salary and benefits are much higher than those of traditional industries. The technology industry still attracts many 
young job seekers in Taiwan. To achieve sustainable development, the organization should avoid the loss of human resources and pay attention to the employees' perception of well-being.

Well-being is what everyone desires most, and it is also the goal that people have always wanted to pursue. Li and Yu (2014) believed that in the past, people thought that if they avoided suffering, they would feel happy. However, modern people are more progressive in pursuing well-being. Butt et al. (2020) believed that happier people feel that work is more important. Therefore, the study of subjective well-being is widely used in organizational-related research since subjective wellbeing can effectively make employees actively participate in work so that productivity and performance would be improved. Also, it is related to whether the company can maintain a competitive advantage in the future, subjective well-being has received considerable attention within the organization (Kuykendall et al., 2015), and for its effect on the workplace performance (Okun, 2022).

In recent years, newspapers, magazines, and news media have often mentioned the term "happy enterprise" in Taiwan. A happy enterprise would provide a happy workplace that can help promote the well-being of employees, thereby bringing valuable atmosphere to the organization (Wilks and Neto, 2013). Taiwan 1,111 Manpower Bank cooperated with major news media, such as China Times to jointly promote several "happy enterprises" selection activities to commend happy companies. From the winner list of 2011 to 2021, most of them belong to the technology industry (Huang and Yen, 2018). The technology industry is trying hard to promote a happy workplace. Because the nature of the work is in line with the trend of the times, employees in the technology industry must constantly improve to keep up with the pace of the times, and their work pressure is relatively higher than in other industries. Although the salary and benefits of the technology industry are better than those of other industries, it is worth exploring whether it will increase the subjective well-being of employees. Therefore, this study uses the subjective well-being of employees in the technology industry as the dependent variable, and workplace well-being as the independent variable, to explore the relationship between workplace well-being and subjective well-being.

Job involvement is the attitude of the worker, which will be reflected in the work, organization, colleagues, and situation. Work input would affect the behavior of the worker (Hwang and Han, 2015; Wang and Chang, 2016). Hsu et al. (2019) believed that job involvement is more effective in assessing employees' work attitudes than job satisfaction. Then, Lin and Tien (2018) also pointed out that the work of all employees, with the company's good leadership, would improve organizational performance. In the technology industry, if employees want to have outstanding work performance, they must also have work more. However, whether work input will bring more happiness remains to be further verified. This study uses job involvement as a mediating variable to explore whether the provision of a happy workplace will make employees more engaged in work and have a positive impact on subjective well-being.
Flow was defined as a source of energy that allows people to concentrate on what they want to do (Kim and Thapa, 2018; Wang et al., 2018). It can also be regarded as a pleasant state and experience. Kim and Hall (2019) studied the impact of consumer virtual reality (VR) travel hedonic behavior on continuous use and the impact of subjective well-being. It was found that the perceived pleasure of flow state has a significant impact on subjective well-being. It was also confirmed that if employees focus on the task's flow experience, they will help improve their happiness at work (Kawalya et al., 2019). A meaningful feeling will bring intrinsic motivation and make employees work happily. To make them think that work is a pleasant experience, which is of great help to the improvement of happiness. Therefore, this research also explores the relationship between flow and subjective well-being, and whether the happy workplace will influence subjective well-being through flow. Based on the above, this research uses employees in the technology industry as the survey object to explore the dualmediation model of the workplace well-being on subjective well-being, in order to understand the direct and indirect effects of workplace well-being on subjective well-being.

\section{LITERATURE REVIEW}

\section{Subjective Well-Being}

Subjective well-being is defined as individuals' cognitive and affective evaluations of their own lives (Seligman, 2018). Subjective well-being refers to an individual's subjective emotional perception of the overall life (Lin et al., 2014; Shang et al., 2018). It is everyone's pursuit of life. Taheri et al. (2019) focused on the personnel of Iranian public organizations as the research object. The study found that both personal and organizational factors affect the subjective well-being of employees. Moreover, Horowitz (2016) explored the impact of five dimensions (individual task freedom, monetary compensation, work safety, low work intensity, and safe working conditions) on the subjective well-being of American employees' work quality. The research results showed that the quality of work affected subjective well-being by improving social life, promoting physical health, and increasing leisure time. Then, Darvishmotevali and Ali (2020) explored the relationship between job insecurity, subjective well-being, and job performance with 250 hotel employees. The study found that subjective wellbeing has a positive impact on employees' work performance. From the above literature discussion, subjective well-being would be affected by organizational factors or conditions, and subjective well-being would affect job performance. Also, Butt et al. (2020) believed that people who are more conscious of well-being would take their work more seriously, be more dedicated, and have higher job satisfaction. Therefore, the organization has turned its attention to how to ensure the well-being of employees has become an important task for management.

\section{Workplace Well-Being}

Since employee well-being is highly correlated with job satisfaction (Tamariz et al., 2021), job performance, and productivity (Kuykendall et al., 2015), the company should provide an environment that 
can create happiness for employees to feel well-being in the workplace. Wok and Hashim (2015) stated that happiness in the workplace is also considered an essential element of successful organizations. A happy workplace can retain talent on the one hand and attract new employees on the other. Because employees' expectations of the workplace are expanding, many are looking for jobs that offer personal development, fulfillment, and wellbeing (Slemp et al., 2015). Then, Li et al. (2020) studied 356 Chinese healthcare workers and found that non-workaholics' perceptions of happiness in the workplace decreased as work intensity increased. Also, Singh et al. (2019) explored the relationship between self-efficacy and well-being in the workplace with 527 full-time executives in Indi. Research findings showed that selfefficacy has a significant relationship with workplace well-being. Furthermore, the result suggests that the relationship between self-efficacy and workplace well-being was stronger among executives with a high level of sustainability practices and vice versa. Most school graduates would choose tech-related industry as their first job because the technology industry has better pay, benefits, and working environment compared with other industries. Therefore, this study determined workplace well-being as the independent variable and explore its effect on subjective well-being through flow.

\section{Job Involvement}

According to Chukwusa (2020), job involvement means that employees not only work to earn a living but also more importantly, derive natural satisfaction from the work itself. They not only work on time but also are willing to work overtime without complaining. Lee et al. (2020) believed that job involvement is a key factor contributing to personal growth, satisfaction, and workplace goal-directed behavior. Moreover, Rehman et al. (2020) examined different leadership behaviors, job involvement, and performance of 757 Chinese and Middle Eastern managers and found that leadership behaviors affect employees' job involvement and performance. Then, Lee et al. (2020) conducted a survey of 360 employees in the travel industry. The research results found that job involvement positively influences well-being. In summary, job involvement affects work performance and plays an important role in personal well-being. In addition, job involvement is associate with work-family conflict and workers' age (Lambert et al., 2020).

\section{Flow}

Kawalya et al. (2019) defined flow as the overall feeling that employees feel when they are fully engaged. According to Zhou (2019) and Gao et al. (2015), flow is an experience that people feel when they are fully focused on their actions. When a person is in a state of flow, people become absorbed in the activity they are engaged in and lose their perception of the outside world. In recent years, the concept of flow experience has been widely applied in social commerce (Zhou, 2019), online games (Chen et al., 2018), or leisure domain (Tang et al., 2019), and there are also studies that apply the concept of flow to the topic of work (Kawalya et al., 2019). Therefore, this study attempts to incorporate flow in to the model to investigate the effect of flow on subjective well-being and whether workplace well-being can further affect subjective well-being through flow.

\section{Research Hypotheses}

\section{Related Works of Workplace Well-Being and Subjective Well-Being}

Workplace well-being and subjective well-being are more and more popular in academic and business settings. For example, Kun and Gadanecz (2019) studied the relationship between workplace well-being and psychological capital. They proved that workplace well-being would impact psychological capital significantly. The findings of Sahai and Mahapatra (2020) also indicated that job involvement and job satisfaction play important roles in workplace well-being. Workplace wellbeing is considered essential for a successful business and would increase employee psychological functioning and psychological well-being, including hedonic (e.g., affective and satisfaction; DiPietro et al., 2020) and affective (e.g., engagement; Wardani et al., 2020; Koon and Ho, 2021). The provision of workplace well-being contributes to the happiness of employees. The technology industry is likely to increase the subjective well-being of employees because of the excellent benefits, working environment, and promotion path it offers. Therefore, based on the above literature, this study proposes the hypothesis $\mathrm{H} 1$ as:

H1: Workplace well-being has a positive and significant impact on employees' subjective well-being.

\section{Related Works of Workplace Well-Being and Subjective Well-Being}

The more employees work, the higher employees' awareness of work characteristics, the more employees perceive intrinsic value, and the higher employees' subjective well-being would be. Lambert et al. (2018) explored the relationship between work stress, job involvement on well-being. They found that there is a positive effect of job involvement on well-being. Moreover, a study by Zhou et al. (2019) found that employees perceive themselves to be closely related to the organization when their sense of identification with the organization is higher. Employees who want to be praised by the organization would be more engaged in their work, which in turn would lead to a greater sense of well-being. Then, Lee et al. (2020) explored the relationship between job involvement and wellbeing among cruise ship employees during their travel experience. Their research findings showed that working under a pleasant travel experience not only has a positive impact on job involvement but also produces a high sense of well-being. Therefore, this study proposes the hypothesis $\mathrm{H} 2$ as:

H2: Job involvement has a positive and significant impact on subjective well-being.

Related Works of Flow and Subjective Well-Being Flow has a positive relationship to subjective well-being. For example, Kim and Hall (2019) found that consumers' perceived pleasure of flow states had a significant effect on subjective well-being. Since the flow is to enter the "no-self state," in 
this state, one forgets about time, space, and even oneself. When one focuses only on what he/she is doing, one feels a unity of mind and body, happiness, and joy. Kim and Hall (2019) explored the relationship between flow and subjective well-being using virtual reality (VR) travel as a target scenario. The study results also confirmed the highly significant effect of consumers' perceived pleasure and flow state on subjective well-being. Moreover, Kawalya et al. (2019) explored the relationship between flow experiences on psychological capital and well-being in the workplace with a sample of 800 nurses. The findings revealed a significant positive relationship between flow experiences on psychological capital in the workplace and well-being. According to the above literature, this study proposes the hypothesis $\mathrm{H} 3$ as:

H3: Flow has a positive and significant impact on subjective well-being.

\section{Related Works of Workplace Well-Being and Job Involvement}

Though workplace well-being is multidimensional (Na'imah et al., 2021), it is relevant to job involvement. Brunetto et al. (2012) surveyed 193 police officers in Australia to examine the impact of emotional intelligence on job involvement and workplace well-being. Research findings indicated that emotional intelligence affects job involvement and workplace well-being. Moreover, Huang et al. (2016) targeted human resource managers/professionals in manufacturing, financial, and service companies in Taiwan to determine the relevance of workplace well-being and job involvement. The technology industry often invests a lot of resources to promote work and life balance outside of work, which will make employees more willing to commit to their work. Therefore, this study proposes the hypothesis $\mathrm{H} 4$ as:

H4: Workplace well-being has a positive and significant impact on job involvement.

\section{Related Works of Workplace Well-Being and Flow}

There is a correlation between workplace well-being and mind flow. Wok and Hashim (2015) suggested that the focus of workplace well-being is on the individual's experience of the work environment. The concept is therefore similar to flow, as the components of flow include clear goals, clear feedback, a sense of control, etc. All of these are consistent with the environment and conditions offered by workplace well-being. That is when an organization can provide enough conditions to make people feel well-being, then more employees have no worries in this environment. The more employees can show their best working ability, the more they can naturally experience joyful emotions at work, concentrate on work, have fun at work and forget about the passage of time.

Scholars pointed out that a happy and healthy workplace allows employees to develop themselves, interact interpersonally, and use skills. A good workplace should have reasonable goals, a balance of personal safety, supportive supervision, adequate rewards for work, and meaningful work development. When employees work in such a workplace, they should be able to devote themselves. Therefore, if employees in the technology industry could experience workplace well-being, they would spend most of their time at work. This study proposes the hypothesis $\mathrm{H} 5$ as:

H5: Workplace well-being has a positive and significant impact on flow.

\section{Related Job Involvement and Flow}

Job involvement is the degree to which a person is fully dedicated to his or her work. If employees gain great job satisfaction, they are willing to put more effort into the work or involve themselves more in the job with no complaints. Flow is the state of total concentration and forgetfulness when doing something. Flow is more than just work input; it is the overall feeling that employees have when they are doing their best. It can infer that the higher the job involvement, the more satisfied employees can receive, and which makes them experience more flow under such a workplace.

Therefore, there is a correlation between job involvement and the state of flow. Fan (2013) investigated the relationship between organizational belongingness, mobility experience, and positive behavior of salon employees in a Taiwanese salon organization. The research findings showed that flow experience is highly correlated with employee motivation and the ability to meet workplace challenges. Moreover, Peifer et al. (2020) studied how incomplete tasks at work were related to flow experiences with 93 employees as subjects. The results of the study showed that a person's job involvement in an unfinished task was associated with flow experiences. Accordingly, it can be inferred that as employees in the technology industry become more engaged in their work, if they can enter the state of flow. Therefore, this study proposes the hypothesis $\mathrm{H} 6$ as:

H6: Job involvement has a positive and significant impact on flow.

Table 1 shows the research hypothesis and its references, and Figure 1 displays the research framework.

\section{RESEARCH DESIGN}

\section{Questionnaire Design}

The questionnaire is divided into two parts: the first part is the basic personal information of technology employees in terms of gender, marriage, job title, and education level. The second part is about the factors impacting the subjective wellbeing of employees in the technology industry, which are three dimensions, namely, workplace well-being, job involvement, and flow. The questionnaire was designed using a seven-point Likert scale, with " 1 " indicating strongly disagree and " 7 " 
indicating strongly agree. After the design of the questionnaire was completed, it was reviewed by industry experts and scholars and gradually revised for improvement. The questionnaire contains four dimensions, 24 measurement indicators, and literature sources are shown in Table 2.

\section{Sampling Method}

This study focuses on the subjective well-being of employees in the technology industry; therefore, this study takes employees in the technology parks in southern Taiwan as the target population. The questionnaires were distributed in paper form from July 1 to July 31, 2021. During this period, the epidemic was controlled well in Taiwan, and the technological employees were affected to a very limited extent. The study adopted a cluster and convenience sampling method and was distributed with the assistance of the company's human resources manager. A total of 300 questionnaires were distributed in total, excluding 44 questionnaires that were incompletely filled out and those with the same answer options. A total of 256 valid questionnaires were finally collected, with a valid questionnaire collection rate of $85 \%$.

\section{Data Analysis}

The data analysis methods used in this study included multivariate analysis (SPSS) and structural equation modelling (SEM). In the SPSS section, this study would conduct frequency distribution and item statistical analysis, and in the SEM section, measurement models (validated factor analysis) and structural models were included. The measurement model would consider the appropriateness of each measure for the interpretation of the components. The structural model can specify the relationship between the components.

\section{RESULTS}

\section{Descriptive Statistical Analysis}

From the frequency distribution table, the basic information of the survey includes four items, which are gender, marital

TABLE 1 | Summary of research hypothesis literature.

\begin{tabular}{|c|c|c|}
\hline Hypothesis & Variable relationship & References \\
\hline $\mathrm{H} 1$ & $\begin{array}{l}\text { Workplace well- } \\
\text { being } \rightarrow \text { Subjective well- } \\
\text { being }\end{array}$ & $\begin{array}{l}\text { Kun and Gadanecz (2019) and Sahai } \\
\text { and Mahapatra (2020) }\end{array}$ \\
\hline $\mathrm{H} 2$ & $\begin{array}{l}\text { Job } \\
\text { involvement } \rightarrow \text { Subjective } \\
\text { well-being }\end{array}$ & $\begin{array}{l}\text { Wang and Chang (2016), Zhou et al. } \\
\text { (2019), and Lee et al. (2020) }\end{array}$ \\
\hline H3 & Flow $\rightarrow$ Subjective well-being & $\begin{array}{l}\text { Kawalya et al. (2019) and Kim and } \\
\text { Hall (2019) }\end{array}$ \\
\hline $\mathrm{H} 4$ & $\begin{array}{l}\text { Workplace well-being } \rightarrow \text { Job } \\
\text { involvement }\end{array}$ & $\begin{array}{l}\text { Brunetto et al. (2012), Huang et al. } \\
\text { (2016), and Darvishmotevali and Ali } \\
\text { (2020) }\end{array}$ \\
\hline H5 & $\begin{array}{l}\text { Workplace well- } \\
\text { being } \rightarrow \text { Flow }\end{array}$ & $\begin{array}{l}\text { Wilks and Neto (2013) and Wok and } \\
\text { Hashim (2015) }\end{array}$ \\
\hline H6 & Job involvement $\rightarrow$ Flow & Fan (2013) and Peifer et al. (2020) \\
\hline
\end{tabular}

status, education level, and position. The largest number of respondents were female, with 138 (53.91\%). The marital status, the largest number of respondents was married, with 132 (51.56\%). Among the education level, the largest number of students, 152 (59.38\%), was university students. Among the job position, the largest number of employees is at the basic level, with $170(66.41 \%)$ as shown in Table 3.

Table 4 below shows that the total number of valid questionnaires was 256. The mean value ranged from 4.02 to 5.22 , the standard deviation ranged from 1.1 to 1.83 , the skewness value ranged from -0.72 to 0.48 , and the kurtosis value ranged from -1.33 to -0.21 , which met the criteria of absolute skewness value less than two and absolute kurtosis value less than seven proposed by Kline (2015). This means that the data are consistent with the normal distribution. From the table below, the mean value of FLO02 is 5.22 and the mean value of JIN06 is 4.02, which means that the respondents agree most with FLO02 and less with JIN06. The lowest score is "Work is everything to me" and the highest score is "When working, I think time passes quickly." This means that work is considered only a part of technological employees' lives, and they are fully engaged in their works so they forget about the time.

\section{Measurement Model}

The most approximate estimation method was used to measure the model. The estimated parameters included factor loadings, reliability, convergent validity, and discriminant validity. According to the criteria proposed by Hair et al. (1998); Nunnally (1994) and Fornell and Larcker (1981) for convergent validity:

1. Standardized factor loading for each indicator variable should be greater than 0.50 ;

2. Composite reliability should be higher than 0.60 ; and

3. Average variance extracted should be higher than 0.50 .

The standardized factor loadings of this study ranged from 0.604 to 0.947 , all of which were within the range, indicating that each question had question reliability. The reliability of the study components ranged from 0.899 to 0.964 , all of which exceeded 0.7 and met the criteria suggested by scholars, indicating that each component had good internal consistency. Finally, the average variance extractions ranged from 0.605 to 0.857 , all of which were higher than 0.5 and met the criteria of Hair et al. (1998) and Fornell and Larcker (1981), indicating good convergent validity for each construct as shown in Table 5.

In terms of discriminant validity, a more rigorous AVE method was used in this study. Fornell and Larcker (1981) stated that discriminant validity should also consider the correlation between convergent validity and construct. Therefore, it is recommended that the square root of AVE for each construct should be greater than the correlation coefficient between that construct and the other constructs. The root mean square of AVE for each construct of the diagonal of this study is larger than the correlation coefficient outside the 
diagonal, so each construct of this study has good discriminant validity as shown in Table 6.

\section{Structural Model}

This study applies the 194 international journal papers examined in Jackson, Gil-laspy, and Purc-Stephenson (Jackson et al., 2009) as the blueprint for applying the model fitness analysis and reports the results of this study using the nine most widely used fitness indicators. The model fit metrics should meet the recommended thresholds (Schumacker and Lomax, 2016), e.g., $\chi^{2}$ should be as low as possible, and since $\chi^{2}$ is very sensitive to large samples, it must be evaluated with chi-square values/ degrees of freedom. Good model fitness chi-square value/degrees of freedom should be less than 3. After the Bollen-Stine Bootstrap modified model fit, all the fit indicators of this study were passed, indicating that the fit of this study was good as shown in Table 7 .

The results of the path coefficient were calculated. Workplace well-being $(b=0.221, p<0.001)$, job involvement $(b=0.202$, $p=0.013)$, and flow $(b=0.522, p<0.001)$ significantly influenced subjective well-being. Workplace well-being $(b=0.506, p<0.001)$ significantly influenced job involvement. Workplace well-being $(b=0.143, p<0.001)$ and job involvement $(b=0.306, p<0.001)$ significantly affected flow. These results supported the research questions of this model. The explained variation of workplace

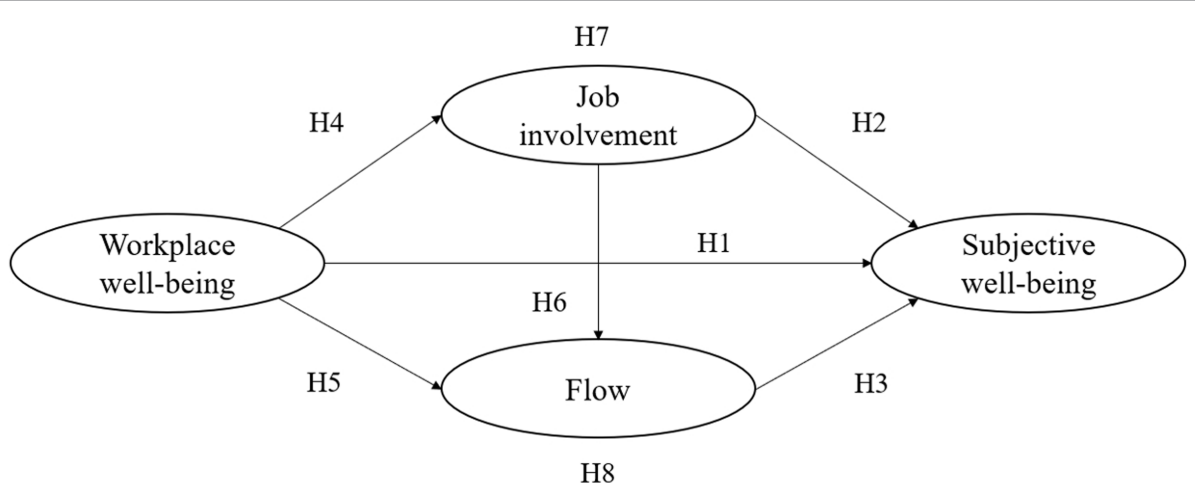

FIGURE 1 | Research framework.

TABLE 2 | Summary of measurement indicators.

\begin{tabular}{|c|c|c|c|}
\hline Variable & No. & Indicator & References \\
\hline Subjective well-being & $\begin{array}{l}\text { SWB1 } \\
\text { SWB2 } \\
\text { SWB3 } \\
\text { SWB4 }\end{array}$ & $\begin{array}{l}\text { In most respects, my life has been close to ideal } \\
\text { I think my living conditions are very good } \\
\text { I am satisfied with my life } \\
\text { So far, I've gotten the important things I want in life }\end{array}$ & Butt et al. (2020) \\
\hline Workplace well-being & $\begin{array}{l}\text { WWB1 } \\
\text { WWB2 } \\
\text { WWB3 } \\
\text { WWB4 } \\
\text { WWB5 } \\
\text { WWB6 } \\
\text { WWB7 } \\
\text { WWB8 }\end{array}$ & $\begin{array}{l}\text { My company's salary package is better than the industry } \\
\text { My company takes employee benefits very seriously } \\
\text { My company provides education and training and cares about the growth of } \\
\text { our employees. } \\
\text { My company has a flexible working hours system that allows for more } \\
\text { autonomy at work } \\
\text { My company has an open line of communication that allows employees to } \\
\text { fully express their opinions } \\
\text { My company offers opportunities for promotion and development } \\
\text { I get along well with my workmates } \\
\text { My company would invest in social care and give back to society }\end{array}$ & $\begin{array}{l}\text { Chiou (2014) and Huang and Yen } \\
\text { (2018) }\end{array}$ \\
\hline Job involvement & $\begin{array}{l}\text { JIN } 1 \\
\text { JIN } 2 \\
\text { JIN3 } \\
\text { JIN } 4 \\
\text { JIN } 5 \\
\text { JIN6 }\end{array}$ & $\begin{array}{l}\text { I like to focus on my work most of the time } \\
\text { I think my work is very important to me } \\
\text { Most of my personal goals in life are work-oriented } \\
\text { I have a very close connection with my current job } \\
\text { Most of my interests revolve around my work } \\
\text { Work is everything to me }\end{array}$ & Zopiatis et al. (2014) \\
\hline Flow & $\begin{array}{l}\text { FLOW1 } \\
\text { FLOW2 } \\
\text { FLOW3 } \\
\text { FLOW4 } \\
\text { FLOW5 } \\
\text { FLOW6 }\end{array}$ & $\begin{array}{l}\text { I know exactly what I need to strengthen in my work } \\
\text { When working, I think time passes quickly } \\
\text { When working, I feel that time is not enough } \\
\text { When working, I enjoy it } \\
\text { Working in the field relaxes my mind and body } \\
\text { Working in the job can meet my wants }\end{array}$ & Chang (2017) and Lin et al. (2019) \\
\hline
\end{tabular}


TABLE 3 | Frequency distribution table.

\begin{tabular}{|c|c|c|c|c|c|}
\hline Variable & Value label & Value & Frequency & Valid percentage & Cummulated percentage \\
\hline \multirow[t]{3}{*}{ Gender } & Male & 1 & 118 & 46.09 & 46.09 \\
\hline & Female & 2 & 138 & 53.91 & 100.00 \\
\hline & & Total & 256 & 100.0 & \\
\hline \multirow[t]{3}{*}{ Marital status } & Unmarried & 1 & 124 & 48.44 & 48.44 \\
\hline & Married & 2 & 132 & 51.56 & 100.00 \\
\hline & & Total & 256 & 100.0 & \\
\hline \multirow[t]{6}{*}{ Education } & Under high school & 1 & 8 & 3.13 & 3.13 \\
\hline & Diploma & 2 & 21 & 8.20 & 11.33 \\
\hline & University & 3 & 152 & 59.38 & 70.70 \\
\hline & Master & 4 & 68 & 26.56 & 97.27 \\
\hline & Doctor & 5 & 7 & 2.73 & 100.00 \\
\hline & & Total & 256 & 100.0 & \\
\hline \multirow[t]{5}{*}{ Job position } & Basic employee & 1 & 170 & 66.41 & 66.41 \\
\hline & Basic supervisor & 2 & 47 & 18.36 & 84.77 \\
\hline & Middle supervisor & 3 & 22 & 8.59 & 93.36 \\
\hline & Senior supervisor & 4 & 17 & 6.64 & 100.00 \\
\hline & & Total & 256 & 100.0 & \\
\hline
\end{tabular}

TABLE 4 | Descriptive statistics analysis.

\begin{tabular}{lllllr}
\hline Variable & $\boldsymbol{N}$ & Mean & Std. dev. & Kurtosis & Skewness \\
\hline JIN01 & 256 & 5.11 & 1.32 & -0.94 & -0.17 \\
JIN02 & 256 & 5.11 & 1.29 & -1.02 & -0.22 \\
JIN03 & 256 & 4.67 & 1.37 & -0.63 & -0.01 \\
JIN04 & 256 & 4.80 & 1.27 & -0.84 & -0.01 \\
JIN05 & 256 & 4.38 & 1.47 & -0.61 & 0.04 \\
JIN06 & 256 & 4.02 & 1.68 & -0.73 & 0.02 \\
WWB01 & 256 & 4.08 & 1.83 & -1.08 & -0.07 \\
WWB02 & 256 & 4.13 & 1.73 & -0.93 & 0.08 \\
WWB03 & 256 & 4.23 & 1.64 & -0.70 & -0.11 \\
WWB04 & 256 & 4.15 & 1.67 & -0.78 & -0.01 \\
WWB05 & 256 & 4.29 & 1.67 & -0.76 & -0.15 \\
WWB06 & 256 & 4.11 & 1.68 & -0.87 & -0.14 \\
WWB07 & 256 & 4.93 & 1.59 & -0.32 & -0.72 \\
WWB08 & 256 & 4.38 & 1.58 & -0.59 & -0.26 \\
FLOW01 & 256 & 5.21 & 1.10 & -0.46 & -0.04 \\
FLOW02 & 256 & 5.22 & 1.19 & -1.33 & 0.19 \\
FLOW03 & 256 & 4.95 & 1.15 & -1.04 & 0.40 \\
FLOW04 & 256 & 4.59 & 1.33 & -0.41 & 0.30 \\
FLOW05 & 256 & 4.26 & 1.39 & -0.34 & 0.34 \\
FLOW06 & 256 & 4.53 & 1.31 & -0.44 & 0.21 \\
SWB01 & 256 & 4.76 & 1.10 & -0.29 & 0.24 \\
SWB02 & 256 & 4.63 & 1.22 & -0.21 & 0.30 \\
SWB03 & 256 & 4.71 & 1.15 & -0.41 & 0.48 \\
SWB04 & 256 & 4.64 & 1.35 & -0.39 & 0.06 \\
\hline & & & & & \\
\hline
\end{tabular}

well-being, job involvement, and flow to subjective well-being was $64.8 \%$. The explained variation of workplace well-being to job involvement was $62.3 \%$. The explained variation of workplace well-being and job involvement to flow was $57.5 \%$ as shown in Table 8. Research framework path analysis is shown in Figure 2.

\section{Mediation Effect Analysis}

In some indirect effect studies, bootstrapping has been shown to have more statistical power in determining indirect effects than causal and coefficient product methods (MacKinnon et al., 2004; Williams and MacKinnon, 2008). One of the greatest advantages of the self-help method is that the estimation of the indirect effects does not require a normative sampling allocation of the indirect effects unlike the coefficient product method (e.g., B-K method).

From the table below for the analysis of the indirect effect of the mediation model, in the total effect of $\mathrm{WWB} \rightarrow \mathrm{FLO}$, its $p<0.05$, this confidence interval does not contain 0 [0.214-0.384], which means that the total effect holds. In the total indirect effect of WWB $\rightarrow \mathrm{JIN} \rightarrow$ FLO, its $p<0.05$ and this confidence interval did not contain 0 [0.093-0.241], indicating that the total indirect effect holds, representing that the mediating effect holds.

In the total effect of $\mathrm{WWB} \rightarrow \mathrm{SWB}$, its $p<0.05$, this confidence interval does not contain 0 (0.411-0.55), indicating that the total effect holds. For a particular indirect effect $\mathrm{WWB} \rightarrow \mathrm{JIN} \rightarrow \mathrm{SWB}, p>0.05$, the confidence interval contains 0 (-0.006-0.207), indicating that the indirect effect does not hold. WWB $\rightarrow \mathrm{FLO} \rightarrow \mathrm{SWB}, p<0.05$, the confidence interval does not contain $0(0.033-0.152)$, indicating that the indirect effect holds, representing that the mediating effect holds. WWB $\rightarrow \mathrm{JIN} \rightarrow \mathrm{FLO} \rightarrow \mathrm{SWB}, \quad p<0.05$, the confidence interval does not contain 0 (0.041-0.16), indicating that the indirect effect holds, representing that the mediating effect holds. In the total effect of JIN $\rightarrow$ SWB, its $p<0.05$, this confidence interval does not contain $0(0.173-0.587)$, which means that the total effect holds. In the total indirect effect of $\mathrm{IN} \rightarrow \mathrm{SWB}$, its $p<0.05$, this confidence interval does not contain 0 (0.077-0.301), which means the total indirect effect holds, represents the mediating effect holds as shown in Table 9.

\section{DISCUSSION AND CONCLUSION}

\section{Discussion}

The main contribution of this study is to understand the factors of subjective well-being of employees in the technology industry. The main findings are as follows. 
TABLE 5 | Analysis results of the measurement model.

\begin{tabular}{|c|c|c|c|c|c|}
\hline Construct & Item & $\begin{array}{l}\text { Std. factor } \\
\text { loading }\end{array}$ & SMC & CR & AVE \\
\hline \multirow[t]{8}{*}{ WWB } & WWB01 & 0.858 & 0.736 & 0.964 & 0.772 \\
\hline & WWB02 & 0.944 & 0.891 & & \\
\hline & WWB03 & 0.947 & 0.897 & & \\
\hline & WWB04 & 0.853 & 0.728 & & \\
\hline & WWB05 & 0.926 & 0.857 & & \\
\hline & WWB06 & 0.912 & 0.832 & & \\
\hline & WWB07 & 0.707 & 0.500 & & \\
\hline & WWB08 & 0.858 & 0.736 & & \\
\hline \multirow[t]{6}{*}{ JIN } & JIN01 & 0.762 & 0.581 & 0.931 & 0.695 \\
\hline & JIN02 & 0.746 & 0.557 & & \\
\hline & JINO3 & 0.902 & 0.814 & & \\
\hline & JIN04 & 0.862 & 0.743 & & \\
\hline & JIN05 & 0.881 & 0.776 & & \\
\hline & JIN06 & 0.835 & 0.697 & & \\
\hline \multirow[t]{6}{*}{ FLOW } & FLOW01 & 0.604 & 0.365 & 0.899 & 0.605 \\
\hline & FLOW02 & 0.646 & 0.417 & & \\
\hline & FLOW03 & 0.606 & 0.367 & & \\
\hline & FLOW04 & 0.898 & 0.806 & & \\
\hline & FLOW05 & 0.898 & 0.806 & & \\
\hline & FLOW06 & 0.930 & 0.865 & & \\
\hline \multirow[t]{4}{*}{ SWB } & SWB01 & 0.917 & 0.841 & 0.960 & 0.857 \\
\hline & SWB02 & 0.924 & 0.854 & & \\
\hline & SWB03 & 0.947 & 0.897 & & \\
\hline & SWB04 & 0.914 & 0.835 & & \\
\hline
\end{tabular}

Unstd, Unstandardized factor loadings; Std, Standardized factor loadings; SMC, Square Multiple Correlations; CR, Composite Reliability; and AVE, Average Variance Extracted.

TABLE 6 | The discriminant validity of the measurement model.

\begin{tabular}{lccccc}
\hline & AVE & WWB & JIN & FLO & SWB \\
\hline WWB & 0.772 & $\mathbf{0 . 8 7 9}$ & & & \\
JIN & 0.695 & 0.789 & $\mathbf{0 . 8 3 4}$ & & \\
FLO & 0.605 & 0.703 & 0.729 & $\mathbf{0 . 7 7 8}$ & \\
SWB & 0.857 & 0.741 & 0.720 & 0.729 & $\mathbf{0 . 9 2 6}$ \\
\hline
\end{tabular}

The items on the diagonal in bold represent the square roots of the AVE; off-diagonal elements are the correlation estimates.

TABLE 7 | Model fit.

\begin{tabular}{lcc}
\hline Model fit & Criteria & $\begin{array}{c}\text { Model fit of the } \\
\text { research model }\end{array}$ \\
\hline ML $\chi^{2}$ Chi-square value & $\begin{array}{c}\text { The small the better } \\
\text { DF Degrees of freedom }\end{array}$ & $\begin{array}{l}\text { The large the better } \\
\text { Normed Chi-sqr }\left(\chi^{2} / \mathrm{DF}\right)\end{array}$ \\
$\begin{array}{l}\text { Chi-square value/Degrees } \\
\text { of freedom }\end{array}$ & $1<\chi^{2} / \mathrm{DF}<3$ & 246.000 \\
RMSEA & $<0.08$ & 1.582 \\
SRMR & $<0.08$ & \\
TLI (NNFI) & $>0.9$ & 0.048 \\
CFI & $>0.9$ & 0.080 \\
GFI & $>0.9$ & 0.979 \\
AGFI & $>0.9$ & 0.981 \\
\hline
\end{tabular}

First, the employee's workplace well-being has a positive and significant effect on their subjective well-being. The result is similar to the findings of Kun and Gadanecz (2019) and Sahai and Mahapatra's (2020) study. This means that a good or bad work environment affects subjective wellbeing. Second, the employee's job involvement has a positive and significant effect on their subjective well-being. This result is similar to the findings of Zhou et al. (2019), Wang and Chang (2016), and Lee et al. (2020), which represent that the more engaged one is in work, the higher the subjective well-being. Moreover, the employee's flow has a positive and significant effect on their subjective well-being. The result is similar to those of Zhou et al. (2019), Wang and Chang (2016), and Lee et al.s (2020) study. It represents the state of flow of a person is doing something, which affects subjective well-being.

Furthermore, employees' workplace well-being has a positive and significant effect on job involvement. The research finding is similar to those of Brunetto et al. (2012), Huang et al. (2016), and Darvishmotevali and Ali's (2020) research. It means that if the environment, benefits, and treatment in the workplace are very good, the employees' life would be stable and make employees concentrate on their work. Then, an employee's workplace well-being has a positive significant effect on flow. The result is similar to those of Wilks and Neto (2013) and Wok and Hashim's (2015) study. The better the environment and conditions provided by the company, the better it is for the improvement of flow. Finally, employees' job involvement has a positive and significant effect on their flow. This result is similar to the findings of Fan (2013) and Peifer et al.'s (2020) study. It means that when employees concentrate on the work, the employees would have a feeling of forgetfulness and forget that time is passing.

From the above results, the objective workplace well-being does affect the subjective well-being of employees in the technology industry. The commitment to work and the experience of flow are also important factors that affect subjective wellbeing. The employer could improve technological employees' subjective well-being by creating a happy workplace, encouraging their work engagement, and enhancing their mind flow. In particular, a happy workplace has the greatest impact on work engagement, which means that a friendlier working environment in the technology industry can enhance employees' work engagement. The results also illustrated the importance of a happy workplace, which echoes the reason why "happy companies" are elected annually as a benchmark for each business in Taiwan.

In addition, the results of the mediation analysis showed that the mediating effect played by flow was greater than the mediating effect of work engagement in the relationship between workplace well-being and subjective well-being. On the other hand, the present study also found that the mediating effect of flow plays a fully mediating role in job involvement and subjective well-being. The flow is the most important factor in the dual mediators of this study. The flow concentrates people's attention to a focused point, so the external environment has very restricted effects on the individuals' thoughts and perceptions. The flow enables employees to respond to only a specific goal and increase their happiness. Therefore, the flow is an important antecedent 
TABLE 8 | Path analysis.

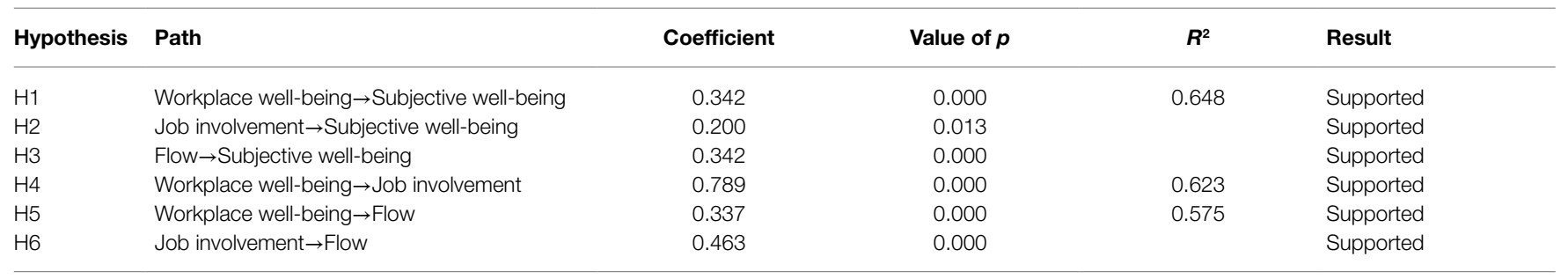

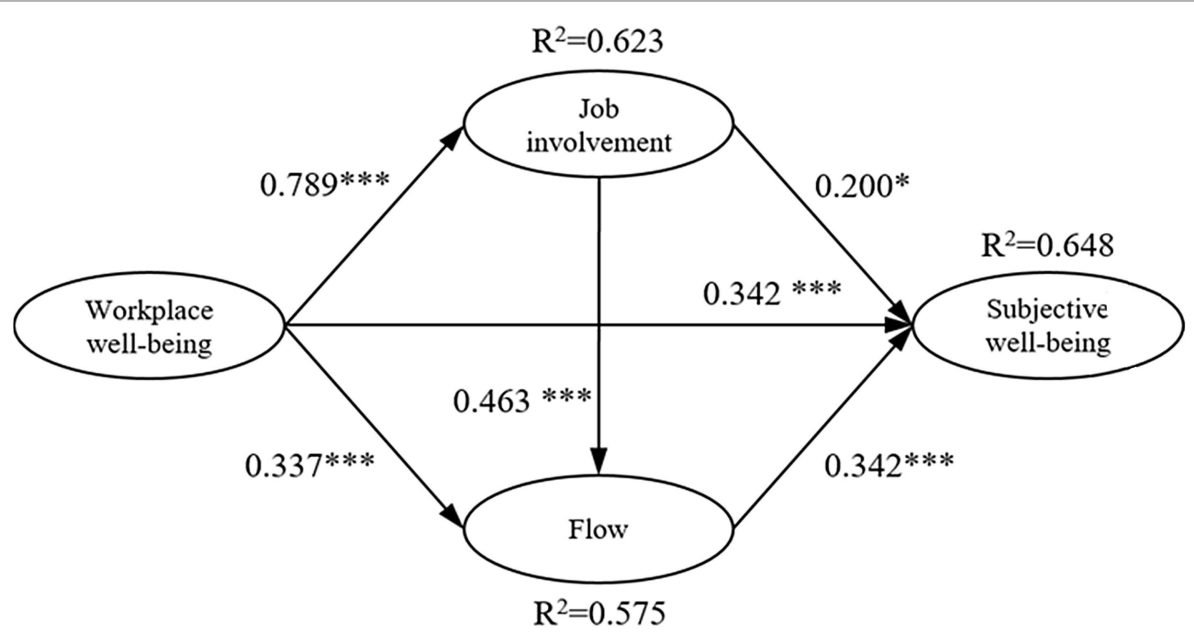

FIGURE 2 | Research framework path analysis diagram.

TABLE 9 | Indirect effect analysis.

\begin{tabular}{|c|c|c|c|c|c|c|}
\hline \multirow[t]{3}{*}{ Effect } & \multirow[t]{3}{*}{ Point estimate } & \multicolumn{3}{|c|}{ Product of coefficients } & \multirow{2}{*}{\multicolumn{2}{|c|}{$\begin{array}{l}\text { Bootstrap 1,000 times } \\
\text { Bias-corrected } 95 \%\end{array}$}} \\
\hline & & \multirow[b]{2}{*}{ SE } & \multirow[b]{2}{*}{$Z$-value } & \multirow[b]{2}{*}{ Value of $p$} & & \\
\hline & & & & & Lower bound & Upper bound \\
\hline \multicolumn{7}{|l|}{ Total effects } \\
\hline $\mathrm{WWB} \rightarrow \mathrm{FLO}$ & .298 & .043 & 6.866 & .000 & .214 & .384 \\
\hline \multicolumn{7}{|l|}{ Total indirect effects } \\
\hline \multicolumn{7}{|l|}{ Direct effects } \\
\hline $\mathrm{WWB} \rightarrow \mathrm{FLO}$ & .143 & .041 & 3.457 & .001 & .070 & .243 \\
\hline \multicolumn{7}{|l|}{ Total effects } \\
\hline$W W B \rightarrow S W B$ & .479 & .035 & 13.821 & .000 & .411 & .550 \\
\hline \multicolumn{7}{|l|}{ Total indirect effects } \\
\hline $\mathrm{WWB} \rightarrow \mathrm{FLO} \rightarrow \mathrm{SWB}$ & .075 & .028 & 2.640 & .008 & .033 & .152 \\
\hline $\mathrm{WWB} \rightarrow \mathrm{JIN} \rightarrow \mathrm{FLO} \rightarrow \mathrm{SWB}$ & .081 & .028 & 2.846 & .004 & .041 & .160 \\
\hline \multicolumn{7}{|l|}{ Direct effects } \\
\hline$W W B \rightarrow S W B$ & .221 & .061 & 3.628 & .000 & .117 & .347 \\
\hline \multicolumn{7}{|l|}{ Total effects } \\
\hline $\mathrm{JIN} \rightarrow \mathrm{SWB}$ & .361 & .101 & 3.577 & .000 & .173 & .587 \\
\hline \multicolumn{7}{|l|}{ Total indirect effects } \\
\hline $\mathrm{JIN} \rightarrow \mathrm{FLO} \rightarrow$ SWB & .160 & .055 & 2.913 & .004 & .077 & .301 \\
\hline \multicolumn{7}{|l|}{ Direct effects } \\
\hline$J I N \rightarrow$ SWB & .202 & .110 & 1.842 & .065 & -.014 & .431 \\
\hline
\end{tabular}


of subjective well-being. It is worthwhile for corporations to work on how to create a work situation that can make employees enter the flow. Therefore, if the workplace wellbeing provided by the technology industry can provide employees with a flow experience, the subjective well-being of employees can be greatly enhanced.

\section{Conclusion}

Workplace well-being has a positive relationship with job involvement, flow, and subjective well-being. On behalf of the corporate world, it is important to start with workplace wellbeing to make employees more engaged in their work, to create a state of flow in their work, and to influence their subjective well-being. The results of this study confirm that Taiwan's technology industry is on the right track to provide workplace well-being. For example, the company can create a good and happy working environment by offering employees better pay than their peers, allowing them to work flexible hours, or allowing the office environment to have a simple gym, a parentchild care center, a café, and afternoon tea time for employees to relax appropriately. Furthermore, the flow experience has a significant positive effect on subjective well-being. Employees need to work in a relaxed environment to improve their flow. Therefore, it is recommended that supervisors can delegate appropriate authority to allow employees to set goals and give them a high degree of autonomy, etc. This is because once employees can have the experience of flow, they can concentrate fully on their work and bring happiness. Finally, job involvement also has a significant positive effect on subjective well-being. So, it is recommended that companies can enhance employees' interest in their work. The HR department can provide aptitude tests with credibility to place employees in the right position for the right job, with the right talent for the right job, and with timely rotations to help enhance the freshness of the job, which in turn increases the enjoyment of the job and enhances their job involvement.

\section{REFERENCES}

Brunetto, Y., Teo, S. T., Shacklock, K., and Farr-Wharton, R. (2012). Emotional intelligence, job satisfaction, well-being and engagement: explaining organisational commitment and turnover intentions in policing. Hum. Resour. Manag. J. 22, 428-441. doi: 10.1111/j.1748-8583.2012.00198.x

Butt, T. H., Abid, G., Arya, B., and Farooqi, S. (2020). Employee energy and subjective well-being: a moderated mediation model. Serv. Ind. J. 40, 133-157. doi: 10.1080/02642069.2018.1563072

Chang, C.-Y. (2017). The study of flow experience, benefits of leisure on wellbeing of yoga participants. J. Sport Recreat. Manag. 14, 74-89.

Chen, C.-S., Lu, H.-P., and Luor, T. (2018). A new flow of location based service mobile games: non-stickiness on Pokémon go. Comput. Hum. Behav. 89, 182-190. doi: 10.1016/j.chb.2018.07.023

Chiou, R.-C. (2014). Best companies to work for-the corporate social responsibility of corporate governance. Operat. Manag. Rev. 10, 54-68.

Chukwusa, J. (2020). Gender difference in organizational commitment, job satisfaction and job involvement: evidence from university library staff. Int. Info. Library Rev. 52, 193-201. doi: 10.1080/10572317.2019.1675444

Darvishmotevali, M., and Ali, F. (2020). Job insecurity, subjective well-being and job performance: the moderating role of psychological capital. Int. J. Hosp. Manag. 87:102462. doi: 10.1016/j.ijhm.2020.102462

\section{RESEARCH LIMITATIONS AND FUTURE RESEARCH RECOMMENDATIONS}

Although the design and implementation of this study were rigorous, there are still some limitations and shortcomings that cannot be avoided. In terms of research data and sample characteristics, the results of this study were only be inferred to the southern part of Taiwan, and the sample characteristics may not represent the whole country. It is suggested that future research could sample technology employees from the other area or countries to explore the antecedent variables that affect the subjective well-being, so the related research regarding subjective well-being could be enriched.

\section{DATA AVAILABILITY STATEMENT}

The raw data supporting the conclusions of this article will be made available by the authors, without undue reservation.

\section{ETHICS STATEMENT}

Ethical review and approval were not required for the study on human participants in accordance with the local legislation and institutional requirements. Written informed consent for participation was not required for this study in accordance with the national legislation and the institutional requirements.

\section{AUTHOR CONTRIBUTIONS}

S-YC: conceptualization, methodology, validation, writingoriginal draft preparation, writing-review and editing, and supervision. $\mathrm{H}-\mathrm{CH}$ : investigation, data curation, formal analysis, and writing-review and editing. All authors contributed to the article and approved the submitted version.

DiPietro, R. B., Moreo, A., and Cain, L. (2020). Well-being, affective commitment and job satisfaction: influences on turnover intentions in casual dining employees. J. Hosp. Mark. Manag. 29, 139-163. doi: 10.1080/19368623.2019.1605956

Fan, S. (2013). The relationships among organizational belonging, flow experience, and positive behaviors of employees in a beauty salon organization. Manag Rev. 32, 131-136.

Fornell, C., and Larcker, D. F. (1981). Evaluating structural equation models with unobservable variables and measurement error. J. Mark. Res. 18, 39-50. doi: $10.1177 / 002224378101800104$

Gao, L., Waechter, K. A., and Bai, X. (2015). Understanding consumers' continuance intention towards mobile purchase: a theoretical framework and empirical study-A case of China. Comput. Hum. Behav. 53, 249-262. doi: 10.1016/j.chb.2015.07.014

Hair, J. F., Black, W. C., Babin, B. J., Anderson, R. E., and Tatham, R. L. (1998). Multivariate Data Analysis. NJ: Prentice Hall Upper Saddle River.

Horowitz, J. (2016). Dimensions of job quality, mechanisms, and subjective well-being in the United States. Sociol. Forum 31, 419-440. doi: 10.1111/ socf. 12251

Hsu, S.-W., Wang, P., Huang, S.-Y., Lou, M.-G., and Liang, Y. (2019). Does Employees' job involvement matter? Study of organizational climate moderating effect on job involvement, satisfaction and organizational commitment. $J$. Global Technol. Manag. Educ. 8, 38-69. 
Huang, L.-C., Ahlstrom, D., Lee, A. Y.-P., Chen, S.-Y., and Hsieh, M.-J. (2016). High performance work systems, employee well-being, and job involvement: an empirical study. Pers. Rev. 45, 296-314. doi: 10.1108/ PR-09-2014-0201

Huang, S.-M., and Yen, C.-L. (2018). An examination of the validity of "happy businesses": examples of Taipei selections. Res. Appl. Psychol. 68, 99-129.

Hwang, P.-C., and Han, M.-C. (2015). Customer orientation, work engagement and customer-focused voice: the moderating roles of challenge and hindrance stressors. J. Hum. Res.Manag. 15, 1-24.

Jackson, D. L., Gillaspy, J. A. Jr., and Purc-Stephenson, R. (2009). Reporting practices in confirmatory factor analysis: an overview and some recommendations. Psychol. Methods 14, 6-23. doi: 10.1037/a0014694

Kawalya, C., Munene, J. C., Ntayi, J., Kagaari, J., Mafabi, S., and Kasekende, F. (2019). Psychological capital and happiness at the workplace: the mediating role of flow experience. Cogent Bus. Manag. 6:1685060. doi: 10.1080/23311975.2019.1685060

Kim, M. J., and Hall, C. M. (2019). A hedonic motivation model in virtual reality tourism: comparing visitors and non-visitors. Int. J. Inf. Manag. 46, 236-249. doi: 10.1016/j.ijinfomgt.2018.11.016

Kim, M., and Thapa, B. (2018). Perceived value and flow experience: application in a nature-based tourism context. J. Destin. Mark. Manag. 8, 373-384. doi: 10.1016/j.jdmm.2017.08.002

Kline, R.B. (2015). Principles and Practice of Structural Equation Modeling. New York: Guilford Publications.

Koon, V. Y., and Ho, T. S. (2021). Authentic leadership and employee engagement: the role of employee well-being. Hum. Syst. Manag. 40, 81-92. doi: 10.3233/ HSM-200943

Kun, A., and Gadanecz, P. (2019). Workplace happiness, well-being and their relationship with psychological capital: a study of Hungarian teachers. Curr. Psychol. 41, 1-15.

Kuykendall, L., Tay, L., and Ng, V. (2015). Leisure engagement and subjective well-being: a meta-analysis. Psychol. Bull. 141, 364-403. doi: 10.1037/ a0038508

Lambert, E. G., Jiang, S., Liu, J., Zhang, J., and Choi, E. (2018). A happy life: exploring how job stress, job involvement, and job satisfaction are related to the life satisfaction of Chinese prison staff. Psychiatry Psychol. Law 25, 619-636. doi: 10.1080/13218719.2018.1473174

Lambert, E. G., Morrow, W., Hogan, N. L., and Vickovic, S. G. (2020). Exploring the association between work-family conflict and job involvement among private correctional staff. J. Appl. Sec. Res. 15, 49-72. doi: 10.1080/19361610.2019. 1636591

Lee, C.-J., Ko, C.-H., Huang, Y.-C., Tsai, Y.-H., and Keng, S. (2020). Effects of tourism experience for job involvement and well-being. Adv. Econ. Bus. 8, 145-153. doi: 10.13189/aeb.2020.080304

Li, Y., Xie, W., and Huo, L. A. (2020). How can work addiction buffer the influence of work intensification on workplace well-being? The mediating role of job crafting. Int. J. Environ. Res. Public Health 17:4658. doi: 10.3390/ ijerph 17134658

Li, R.-H., and Yu, M.-N. (2014). Modeling extraversion and neurotic personality, social support, and subjective well-being of the middle-aged and older people in Taiwan: comparison of structural models. Bull. Educ. Psychol. 45, $455-474$.

Lin, Y.-S., Huang, W.-S., Yang, C.-T., and Chiang, M.-J. (2014). Work-leisure conflict and its associations with well-being: the roles of social support, leisure participation and job burnout. Tour. Manag. 45, 244-252. doi: 10.1016/j. tourman.2014.04.004

Lin, Y.-S., and Tien, C.-C. (2018). The relationships among organizational factors, job involvement, and job satisfaction with: using family conflict as a moderating variable. J. Natl. Formosa Univ. 34, 21-39.

Lin, C.-W., Wang, K.-Y., Chang, S.-H., and Lin, J.-A. (2019). Investigating the development of brand loyalty in brand communities from a positive psychology perspective. J. Bus. Res. 99, 446-455. doi: 10.1016/j.jbusres.2017. 08.033

Mackinnon, D. P., Lockwood, C. M., and Williams, J. (2004). Confidence limits for the indirect effect: distribution of the product and resampling methods. Multivar. Behav. Res. 39, 99-128. doi: 10.1207/s15327906mbr3901_4

Na'imah, T., Tjahjono, H. K., and Madjid, A. (2021). Development of the dimensions of the Teacher's workplace well-being in Islamic school. Adv. Soc. Sci. Educ. Human. Res. 518, 96-103.
Nunnally, J. C. (1994). Psychometric Theory 3E. New York: Tata McGraw-Hill education. Okun, O. (2022). "The positive face of human capital, psychological capital, and well-being," in Research Anthology on Changing Dynamics of Diversity and Safety in the Workforce, (United States: IGI Global), 203-222.

Peifer, C., Syrek, C., Ostwald, V., Schuh, E., and Antoni, C. H. (2020). Thieves of flow: how unfinished tasks at work are related to flow experience and wellbeing. J. Happiness Stud. 21, 1641-1660. doi: 10.1007/s10902-01900149-z

Rehman, S. U., Shahzad, M., Farooq, M. S., and Javaid, M. U. (2020). Impact of leadership behavior of a project manager on his/her subordinate's jobattitudes and job-outcomes. Asia Pac. Manag. Rev. 25, 38-47. doi: 10.1016/j. apmrv.2019.06.004

Sahai, A., and Mahapatra, M. (2020). Subjective well-being at workplace: a review on its implications. J. Critical Rev. 7, 807-810.

Schumacker, E., and Lomax, G. (2016). A Beginner's Guide to Structural Equation Modeling. 4th Edn. New York, NY: Routledge.

Seligman, M. (2018). PERMA and the building blocks of well-being. J. Posit. Psychol. 13, 333-335. doi: 10.1080/17439760.2018.1437466

Shang, S., O'driscoll, M. P., and Roche, M. (2018). Mechanisms linking acculturation, work-family conflict, and subjective well-being among Chinese immigrants in New Zealand. Hum. Resour. Manag. 57, 1097-1109. doi: 10.1002/hrm. 21890

Singh, S. K., Pradhan, R. K., Panigrahy, N. P., and Jena, L. K. (2019). Self-efficacy and workplace well-being: moderating role of sustainability practices. Benchmark. Int. J. 26, 1692-1708. doi: 10.1108/BIJ-072018-0219

Slemp, G. R., Kern, M. L., and Vella-Brodrick, D. A. (2015). Workplace wellbeing: the role of job crafting and autonomy support. Psychol. Well Being 5, 1-17. doi: 10.1186/s13612-015-0034-y

Taheri, F., Jami Pour, M., and Asarian, M. (2019). An exploratory study of subjective well-being in organizations-A mixed method research approach. J. Hum. Behav. Soc. Environ. 29, 435-454. doi: 10.1080/10911359.2018. 1547671

Tamariz, P. E. G., Dueñas, R. M., and Mahmud, M. A. M. (2021). The influence of subjective well-being on the job satisfaction of the Peruvian Millennials. Harv. Deusto Bus. Res. 10, 4-25. doi: 10.48132/hdbr.332

Tang, M.-H., Lin, H.-F., and Lin, P.-C. (2019). He advertising effects of ad formats and social elements on Mobile game applications. J. e-Business 21, 29-76.

Wang, M.-L., and Chang, S.-C. (2016). The impact of job involvement on emotional labor to customer-oriented behavior: an empirical study of hospital nurses. J. Nurs. Res. 24, 153-162. doi: 10.1097/jnr.0000 000000000114

Wang, C.-H., Tsaur, S.-H., Ho, H.-H., and Chen, H.-T. (2018). Recreation specialization, recreationist-environment fit, and flow experience of cyclists. J. Outdoor Recreat. Study 31, 33-59.

Wardani, L. M. I., Wulandari, S., Triasti, P., and Sombuling, A. (2020). The effect of psychological capital on work engagement: employee well-being as a mediator. Test Eng. Manag. 83, 17220-17229.

Wilks, D. C., and Neto, F. (2013). Workplace well-being, gender and age: examining the 'double jeopardy' effect. Soc. Indic. Res. 114, 875-890. doi: 10.1007/s11205-012-0177-7

Williams, J., and Mackinnon, D. P. (2008). Resampling and distribution of the product methods for testing indirect effects in complex models. Struct. Equ. Model. Multidiscip. J. 15, 23-51. doi: 10.1080/107055 10701758166

Wok, S., and Hashim, J. (2015). The moderating effect of employee relations on networking towards workplace happiness among married women in Malaysia. Procedia Soc. Behav. Sci. 211, 306-312. doi: 10.1016/j.sbspro.2015. 11.039

Zhou, T. (2019). The effect of flow experience on users' social commerce intention. Kybernetes 49, 2349-2363. doi: 10.1108/K-03-20190198

Zhou, Q., Chen, G., and Liu, W. (2019). Impact of perceived organizational culture on job involvement and subjective well-being: a moderated mediation model. Soc. Behav. Personal. Int. J. 47, 1-13. doi: 10.2224/ sbp. 7478 
Zopiatis, A., Constanti, P., and Theocharous, A. L. (2014). Job involvement, commitment, satisfaction and turnover: evidence from hotel employees in Cyprus. Tour. Manag. 41, 129-140. doi: 10.1016/j.tourman.2013.09.013

Conflict of Interest: The authors declare that the research was conducted in the absence of any commercial or financial relationships that could be construed as a potential conflict of interest.

Publisher's Note: All claims expressed in this article are solely those of the authors and do not necessarily represent those of their affiliated organizations, or those of the publisher, the editors and the reviewers. Any product that may be evaluated in this article, or claim that may be made by its manufacturer, is not guaranteed or endorsed by the publisher.

Copyright (C) 2022 Chang and Hsu. This is an open-access article distributed under the terms of the Creative Commons Attribution License (CC BY). The use, distribution or reproduction in other forums is permitted, provided the original author(s) and the copyright owner(s) are credited and that the original publication in this journal is cited, in accordance with accepted academic practice. No use, distribution or reproduction is permitted which does not comply with these terms. 